\title{
Importance of Physiotherapy in Rehabilitation of Fractures- A Cross Sectional Questionnaire Based Study
}

\author{
Karishma Desai', Leslie Rani. S² and Brundha MP2 \\ ${ }^{1}$ Saveetha Dental College and Hospitals, Saveetha Institute of Medical \\ and Technical Sciences, Saveetha University, Chennai, India \\ ${ }^{2}$ Lecturer, Department of General Pathology, Saveetha Dental College and Hospitals, Saveetha \\ Institute of Medical and Technical Sciences, Saveetha University, Chennai, India \\ ${ }^{3}$ Associate, professor Saveetha Dental College and Hospitals, Saveetha Institute of \\ Medical and Technical, Sciences, Saveetha University, Chennai, India
}

\section{ABSTRACT}

The process of fracture healing is a complex one. It involves various changes and specific patterns that involve several genes. Fractures are a very common injury to the human body. But its healing process is complicated. After a fracture various processes like cell migration, differentiation, tissue synthesis and growth factor release occur. The role of physiotherapy in fracture healing is an important one. The aim of this study was to create awareness and to analyse the importance of physiotherapy in fracture healing. For this study, a questionnaire consisting 16 questions was circulated among people who have suffered a fracture. The questionnaire was distributed to 100 people and their responses were obtained and analysed.The conclusion of this study would be that the 55\% of the population have undergone a physiotherapy treatment; they should further be made aware of the various benefits of physiotherapy. We also found that a significantly high number of people belonging to the age group of 15-20 are known to have undergone a Physiotherapy treatment for their fracture, a higher number of people belonging to the ages between 15-20 have been relieved of their pain after the Physiotherapy treatment and a higher number of people belonging to the age group 15-20 have had a Physiotherapy treatment once a day. There can be more emphasis on the role of physiotherapy in healing of fractures and how it helps in regaining normal posture, stature, gait and other physical activities after a fracture.

KEY WORDS: PHYSIOTHERAPY, FRACTURES, TRAUMA, HEALING, CALLUS, BLOOD VESSELS.

\section{INTRODUCTION}

The process of fracture healing is a complex one. The healing of fractures involves various changes and specific

\section{ARTICLE INFORMATION}

${ }^{*}$ Corresponding Author: brundha.sdc@saveetha.com Received 13th June 2020 Accepted after revision 8th August 2020 Print ISSN: 0974-6455 Online ISSN: 2321-4007 CODEN: BBRCBA

Thomson Reuters ISI Web of Science Clarivate Analytics USA and Crossref Indexed Journal

\section{Clarivate
Analytics}

NAAS Journal Score 2020 (4.31) SJIF: 2020 (7.728)

A Society of Science and Nature Publication,

Bhopal India 2020. All rights reserved.

Online Contents Available at: http//www.bbrc.in/

Doi: http://dx.doi.org/10.21786/bbrc/13.7/65 patterns with the influence of genes(Marsell and Einhorn, 2011; Markel, 2019). Fracture healing and skeletal tissue repair involve an initial anabolic phase (increase in tissue volume, formation of callus, formation of new blood vessels, ends with chondrocyte apoptosis), a prolonged phase (reduction in volume of callus tissues) and a terminal catabolic phase (cartilage resorption, resorption by osteoclasts)(Saraf, 2007)(Einhorn and Gerstenfeld, 2015). Fractures are a very common injury to the human body. But its healing process is complicated. The immune system plays a very crucial role in the process of wound healing.(Park and Barbul, 2004) After a fracture various 
processes like cell migration, differentiation, tissue synthesis and growth factor release occur (Ghiasi et al., 2017).

Certain trauma, tumour, delayed unions, non-unions, multi fragmentary fractures result in large bone defects. This has been a current challenge for surgeons (Oryan, Monazzah and Bigham-Sadegh, 2015). Usually fractures of the hand result in significant impairment, disabilities and functional limitations (LaStayo, Winters and Hardy, 2003). Multiple factors may influence the natural process of fracture healing. Obesity/fat accumulation is detrimental to bone mass. It may affect bone metabolism by decreasing osteoblast differentiation, promoting osteoclasts activity and bone resorption (Gao et al., 2018).

Physiotherapy means, "The treatment of a disease or deformity by physical methods such as massage, exercise and heat treatment instead of using surgical methods or medications." Physiotherapy has proven to be effective in facilitating the treatment of fractures. The role of the pathologist is to improve the mobility and relieve pain to a significant level for the person affected from the fracture. There can be various methods of physiotherapy that can be employed for the treatment. It can be a single treatment or a mixture of 2 or more treatments. The various methods employed can be ice therapy, scar management, wax therapy, soft tissue massage, and stretching exercises to regain the mobility equivalent to the mobility before the fracture (Physiopedia contributors, September, 26, 2018).

The role of physiotherapy in fracture healing is an important one. Physiotherapy improves the speed of healing, reduction of pain and swelling, improvement in range of movement, the muscles that are weakened will be strengthened, and weight bearing on the affected area is encouraged. (Scutt, 1990) Physiotherapy treatment can help in rehabilitation of the fractured part(s) to full function very quickly (Fracture Treatment, no date). The physiotherapist plays a major role in planning the treatments to accelerate the healing and repair thereby reducing the complications. During the period of immobilisation, the aims of physiotherapy are to reduce edema, maintain function, improve range of movement (ROM) and to teach the patient the use of walking aids like crutches, etc, and to regain the full muscle power and to re-educate full function.

The physiotherapy techniques should be chosen carefully in accordance to the case. The treatment should be gradually intensified but should always be within the capability of the patient. The manner in which the treatment has to be carried out is also decided after analysing how much the patient can perform. Ultrasound is also used in the treatment and it is done to facilitate stretching of the tissues. Simple treatments like heat and ice therapy are done for relaxation of the tissues and management of swelling around the tissues. In some cases, Cryotherapy is also used, which means cooling of muscles and surrounding skin to a temperature so low that it affects the conduction velocity of a nerve. This method is most effective for relieving pain. In cases of restoration of gait, the patient has to be re-educated with various walking aids along with different types of exercises.

Proprioceptive neuromuscular facilitation (PNF) exercises are extremely useful for restoring coordination and motor control besides strengthening exercises (Abd El-Kader, no date). Successful fracture healing is not only determined by complete union but the major factor determining success is by functional use of the affected part after the fracture. Additional techniques in physiotherapy and electro modalities have been used lately specifically for fracture healing. For example, Ultrasound, LASER, Pulsed Electromagnetic Field (PEMF), and electrical stimulation. (Hughes, no date)(Alayat et al., 2017). A program of physiotherapy is necessary after fracture as it prevents deformity by strengthening of the muscles and promotes postural retraining. Physiotherapy serves to facilitate primary mobilisation and that is why it is prescribed after a fracture. (Hoppenfeld and Murthy, 2000; Nakayama, 2001; Dionyssiotis, Yannis \&t Dontas, Ismene Et Economopoulos, D. \&t Lyritis, George., 2007) This study is conducted to analyse and assess the importance given to physiotherapy by fractures patients.

\section{MATERIAL AND METHODS}

Sample collection: A survey was conducted among 150 people who had suffered from a fracture irrespective of their age and gender of November 2019. Nearly 16 valid questions had been prepared and circulated among them.

Inclusion Criteria: Selection criteria include all the people in the general population who are willing to participate in the study.

Exclusion Criteria: Age and gender of the participants, people who did not have a past history of fracture were excluded from the study.

Sampling method: In the present study,the sampling method used is the Random sampling method.

Data Collection and Tabulation: The responses were entered into the excel sheets and then tabulation of the data finally and the question comparison was done. The representation of the data is through the bar graph.

Statistical Analysis: The statistical software used IBM SPSS V22.The statistical tests used were descriptive analysis and Chi Square analysis. Significant $p$ value was set at $<0.05$.

\section{RESULTS AND DISCUSSION}

Physiotherapy is a form of occupational therapy that provides relief from injury, illness and disability. A cross sectional simple randomized questionnaire based survey was conducted among the out patients that visited the 
Orthopaedic department in Saveetha Medical college. The data obtained was compiled and analysed from 100 responses. There were 49\% males and 51\% females that participated in this study as seen in Figure 1. Out of these people, 55\% of the respondents belonged to the age group of 15-20. 28\% of the total were of age 21-25. This can be seen in Figure 2. 9\% of the people that responded to the questionnaire belonged to the age group 26-30 and 8\% of the people were aged 30 or above. Among the people that were a part of the study, various types of treatment was carried out to heal the fracture. The various methods were Surgical, Non-surgical (cast/splint), Physiotherapy and Surgical along with Physiotherapy. 36\% of the respondents had a Non-surgical treatment which included positioning of cast or splint. 31\% of the people underwent a surgery to treat the fracture. 28\% employed Physiotherapy to treat their fractures and only 5\% had got both Surgical treatment as well as Physiotherapy. This is depicted in Figure 3. Figure 4 represents the various etiology of the fracture. The population were given 4 choices, out of which 30\% had fractures due to falling down. 35\% of the respondents suffered a fracture due to any accident. 14\% had fights which led to fractures and 21\% were playing sports which led to a fracture.

Figure 1: Pie chart showing $49 \%$ of the respondents were males (Pink) and 51\% of the respondents were females (Blue).

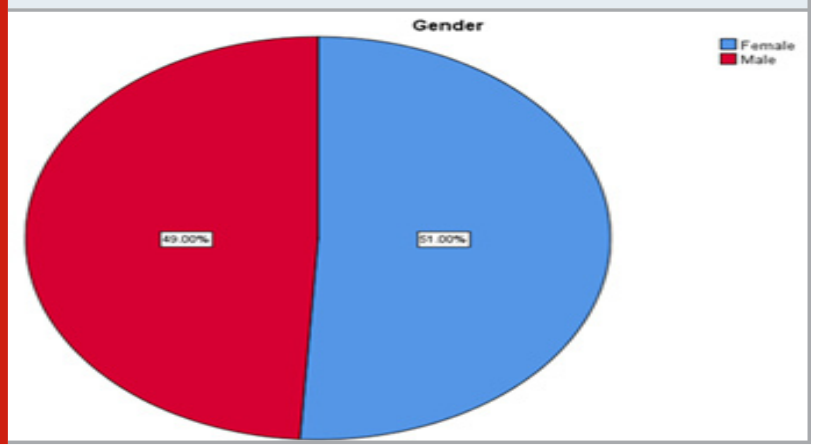

Figure 2: Pie chart represents the age group of the people that participated in the study. 55\% were of the age group 15-20 (Blue). 28\% of the respondents were between the ages of 21-25 (Pink). 9\% of the population belonged to the age group 26-30 (Green) and 8\% of the respondents were aged 30 and above (Orange)

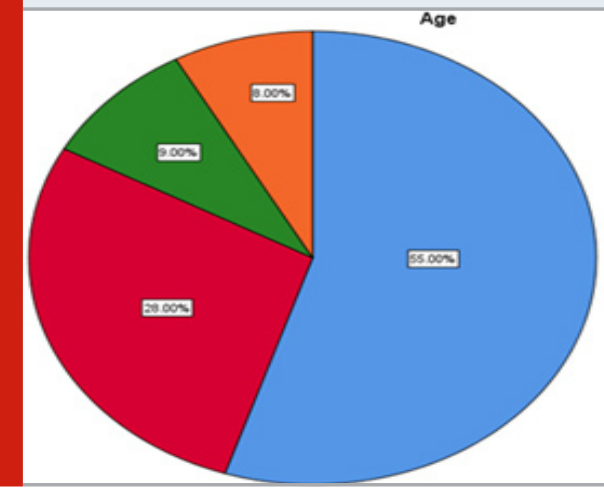

Figure 3: The pie chart represents responses for fracture treatment. Among these responses, 36\% had a Nonsurgical treatment. (Pink) 28\% of the respondents underwent Physiotherapy for treating the fracture. (Green) $31 \%$ people had to get a Surgical treatment done (Orange) and $5 \%$ of the people had undergone Surgical as well as Physiotherapy for treatment of the fracture.

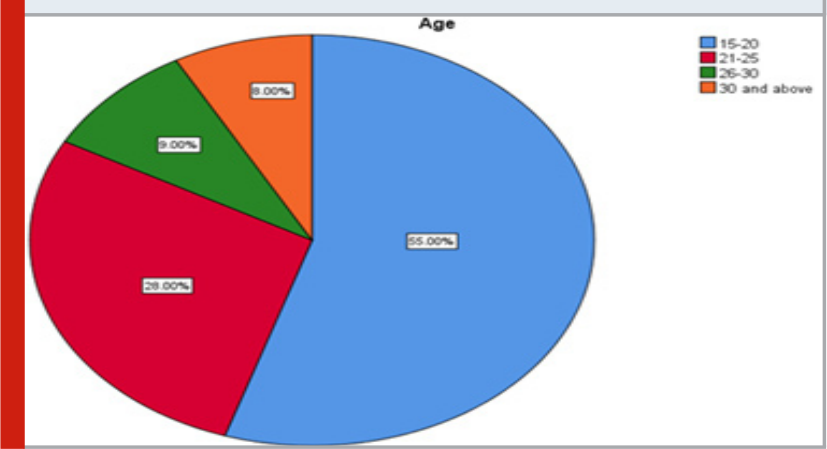

Figure 4: This pie chart depicts the responses for causes of fracture. Among the responses, 14\% had a fracture due to any fights (Pink). 35\% of the people suffered a Road Traffic Accident that led to a fracture. (Green). 21\% of the people suffered a fracture while playing a sport (Orange). While 30\% of them fractured themselves due to a fall. (Blue).

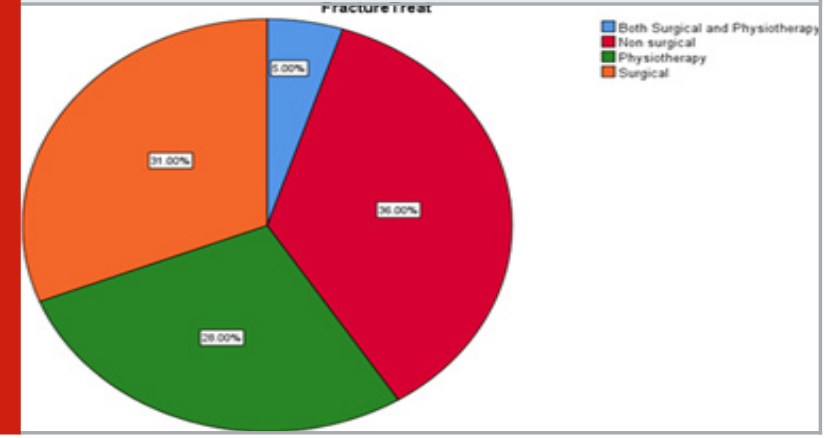

On being asked whether they are taking any measures to reduce the risk of fractures, 33\% of the respondents chose that they are not taking any medications. 32\% respondents mentioned that they have increased their intake of Calcium and Vitamin D. This can be compared to the result obtained by Sprague et al, in which $65.8 \%$ of surgeons indicated that they routinely prescribe vitamin D to fragility fracture patients. (Sprague, Bhandari, et al., 2016; Sprague, Petrisor, et al., 2016) The average time taken for the fracture to heal was observed to be 6-8 weeks. 52\% of the population reported that their fracture healed within this time frame. On the other hand, for $29 \%$ of the respondents, it took more than 10 weeks for the fracture to heal completely.

This is in relation to the study conducted by Leo Massari et al, wherein 12\% of fractures healed after 6 months from trauma. (Massari et al., 2018) When asked if they had any other injuries at the time of the fracture, $47 \%$ of the people did suffer other injuries while 53\% did not suffer any injuries at that time. After the fracture, 
63\% of the people did not find any change in physical activities but on the other hand, 37\% of the people observed a change in physical activity. When it was asked if the patients experienced any other major or minor injuries during the fracture, 56\% did not have any other injuries at that time. But out of the population that was questioned, 44\% did experience other injuries like bruises, lacerations, etc.

Figure 5: Bar graph representing the correlation between Age and Treatment of Fracture using Physiotherapy. X axis represents the Age and the $\mathrm{Y}$ axis represents the number of responses. A significantly high number of people belonging to the age group of 15-20years are known to have undergone a Physiotherapy treatment for their fracture. Chi square analysis was done, Pearson Chi Square Value $=73.847$, the $P$ value was $0.000(p<0.05)$, which was found to be statistically significant. There is a significant number of people that have undergone a Physiotherapy treatment.

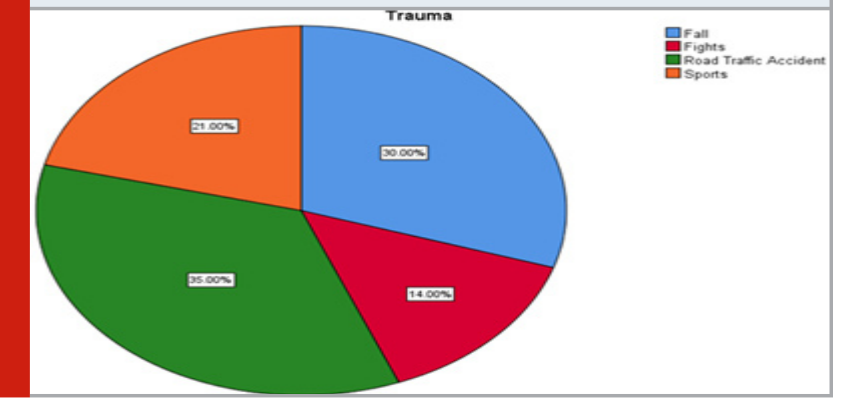

Figure 6. Bar graph representing the association between Age and Pain relief obtained after Physiotherapy. $X$ axis represents Age and the $\mathrm{Y}$ axis represents the number of responses. A higher number of people belonging to the ages between 15-20 have been relieved of their pain after the Physiotherapy treatment. Chi Square Analysis was done, Pearson Chi Square Value $=75.589$, the $P$ value obtained was $0.000(\mathrm{p}<0.05)$, which indicates that it is statistically significant. There is a significant number of respondents that have felt pain relief after a Physiotherapy treatment.

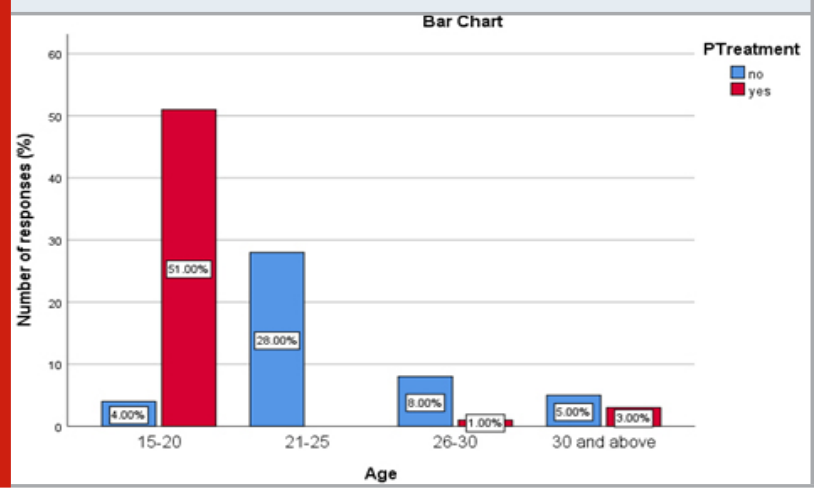

A correlation was drawn between Age and other factors. Figures 5,6 and 7 depict the comparison of Age of the person with 3 factors. It compared age with the following
3 questions; "Have you undergone a Physiotherapy treatment for your fracture?" ; "Was the Physiotherapy treatment pain relieving?" and "How often did you visit the Physiotherapy clinic?” The limitations of our study are considered, it is a pilot study as the sample is small, the time taken for this study is less than one month and this study did not discuss the consequences when proper follow up and physiotherapy exercise are not followed. It also shows that many of the respondents are still not fully aware of the importance and role of physiotherapy in faster healing.

Figure 7: Bar graph representing the association between Age and the frequency of visit to the Physiotherapy clinic. $\mathrm{X}$ axis represents Age while the $\mathrm{Y}$ axis represents the number of responses. Higher number of people belonging to the age group 15-20 have had a Physiotherapy treatment once a day. Chi square analysis was done, Pearson Chi Square Value $=99.513$, the $\mathrm{P}$ value was $\mathbf{0 . 0 0 0}$ ( $p<0.05)$, which was found to be statistically significant. There is a significant number of people that undergo a Physiotherapy treatment once a day.

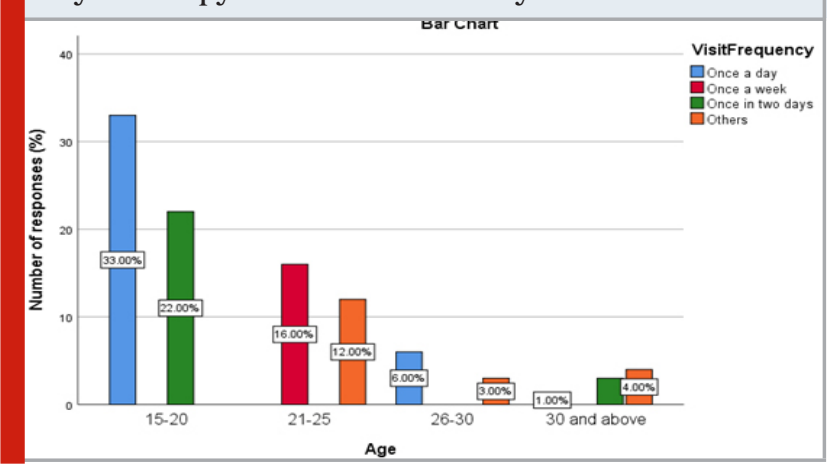

\section{CONCLUSION}

The conclusion of this study would be that the 55\% of the population have undergone a physiotherapy treatment; they should further be made aware of the various benefits of physiotherapy. We also found that a significantly high number of people belonging to the age group of 15-20 are known to have undergone a Physiotherapy treatment for their fracture, a higher number of people belonging to the ages between 15-20 have been relieved of their pain after the Physiotherapy treatment and a higher number of people belonging to the age group 15-20 have had a Physiotherapy treatment once a day. There can be more emphasis on the role of physiotherapy in healing of fractures and how it helps in regaining normal posture, stature, gait and other physical activities after a fracture.

\section{ACKNOWLEDGEMENTS}

The authors are thankful to Saveetha Dental College and Hospitals for the support and the platform given to express our knowledge.

Conflict of Interest: None to declare 


\section{REFERENCES}

Abd El-Kader, S. M. (2017)'Physical Therapy for Fractures and Orthopedic Disorders'. Available at: https://www. kau.edu.sa/Files/0017396/Subjects/Orthopedics(20122013).pdf.

Alayat, M. S. et al. (2017) 'efficacy of Pulsed Electromagnetic Field On Pain And Function In Chronic Mechanical Neck Pain: A Randomized Controlled Trial', International Journal of Physiotherapy and Research, pp. 1930-1936. doi: 10.16965/ijpr.2017.105.

Dionyssiotis, Yannis \& Dontas, Ismene \&t Economopoulos, D. \& Lyritis, George. (2007) 'Rehabilitation after falls and fractures', Journal of musculoskeletal \& neuronal interactions, 8(3), pp. 244-250.

Einhorn, T. A. and Gerstenfeld, L. C. (2015) 'Fracture healing: mechanisms and interventions', Nature Reviews Rheumatology, pp. 45-54. doi: 10.1038/ nrrheum.2014.164.

Fracture Treatment (no date) physio.co.uk. Available at: https://www.physio.co.uk/treatments/physiotherapy/ fracture-treatment.php (Accessed: 28 February, 2020). Gao, F. et al. (2018) 'Effects of obesity on the healing of bone fracture in mice', Journal of orthopaedic surgery and research, 13(1), p. 145.

Ghiasi, M. S. et al. (2017) 'Bone fracture healing in mechanobiological modeling: A review of principles and methods', Bone Reports, pp. 87-100. doi: 10.1016/j. bonr.2017.03.002.

Hoppenfeld, S. and Murthy, V. L. (2000) Treatment and Rehabilitation of Fractures. Lippincott Williams \&t Wilkins.

Hughes, L. E. (no date) 'Fracture Healing'. Available at: https://fourleg.com/media/Fracture $\% 20$ management\%20info.pdf.

LaStayo, P. C., Winters, K. M. and Hardy, M. (2003) 'Fracture healing: Bone healing, fracture management, and current concepts related to the hand', Journal of Hand Therapy, pp. 81-93. doi: 10.1016/s08941130(03)80003-0.

Markel, M. D. (2019) ‘Fracture Healing’, Equine Fracture
Repair, pp. 24-34. doi: 10.1002/9781119108757.ch3. Marsell, R. and Einhorn, T. A. (2011) 'The biology of fracture healing', Injury, pp. 551-555. doi: 10.1016/j. injury.2011.03.031.

Massari, L. et al. (2018) 'Can Clinical and Surgical Parameters Be Combined to Predict How Long It Will Take a Tibia Fracture to Heal? A Prospective Multicentre Observational Study: The FRACTING Study', BioMed Research International, pp. 1-7. doi: $10.1155 / 2018 / 1809091$.

Nakayama, A. (2001) 'Motor Skill and Physical Therapy. Joint Neurophysiological Knowledge Necessary for Physical Therapy of Orthopedic Disorders', Rigakuryoho Kagaku, pp. 151-155. doi: 10.1589/rika.16.151.

Oryan, A., Monazzah, S. and Bigham-Sadegh, A. (2015) 'Bone injury and fracture healing biology', Biomedical and environmental sciences: BES, 28(1), pp. 57-71.

Park, J. E. and Barbul, A. (2004) 'Understanding the role of immune regulation in wound healing', The American Journal of Surgery, pp. S11-S16. doi: 10.1016/s00029610(03)00296-4.

Physiopedia contributors (September, 26, 2018) Fracture, Physiopedia. Available at: https://www.physio-pedia. com/index.php?title=Fracture\&toldid=241449 (Accessed: 27 February 2020).

Saraf, S. (2007) 'Biology of Fracture Healing', Management of Wound Healing, pp. 91-91. doi: 10.5005/jp/books/10459_13.

Scutt, K. (1990) 'Physiotherapy Speeds Healing', Physiotherapy, p. 85. doi: 10.1016/s00319406(10)62506-0.

Sprague, S., Bhandari, M., et al. (2016) 'Prescription of Vitamin D to Fracture Patients', Journal of Orthopaedic Trauma, pp. e64-e69. doi: 10.1097/ bot.0000000000000451.

Sprague, S., Petrisor, B., et al. (2016) 'What Is the Role of Vitamin D Supplementation in Acute Fracture Patients? A Systematic Review and Meta-Analysis of the Prevalence of Hypovitaminosis D and Supplementation Efficacy', Journal of Orthopaedic Trauma, pp. 53-63. doi: 10.1097/bot.0000000000000455. 